\title{
RESSONÂNCIAS MARXIANAS NA AMÉRICA LATINA: A TEORIA DA DEPENDÊNCIA
}

Ivonaldo Leite ${ }^{1}$

\section{RESUMO}

O trabalho tem como objetivo apresentar a teoria da dependência como resultado da influência do pensamento de Marx na América Latina. Para isso, metodologicamente, são visitados os autores clássicos da teoria da dependência, apresentando-se as diferentes versões desta. É realçado, por exemplo, que: 1) a teoria da dependência partiu da metodologia dialética; 2) a dependência é condição para o desenvolvimento dos países centrais; 3) a América Latina está vivendo atualmente novos fenômenos político-sociais que desafiam as análises tributárias da teoria da dependência. Conclusivamente, entre outros aspectos, assinala-se que que, contemporaneamente, tem havido um encontro entre as abordagens da teoria da dependência e a teoria do sistema mundo.

Palavras-chave:Marx, desenvolvimento, subdesenvolvimento, teoria da dependência, América Latina

\section{MARXIAN RESONANCES IN LATIN AMERICA: THE THEORY OF DEPENDENCE}

\begin{abstract}
The paper aims to present the theory of dependence as a result of the influence of Marx's thought in Latin America.In this sense, methodologically, it makes an analysis of the contributions of classical authors of dependency theory, as well as it presents the different versions of such theory. The analysis found out the following results: 1) the theory of dependence has as a basic principle the dialectical methodology; 2) the dependence of the peripheral countries is a condition for the development of the central countries; 3) Latin America is currently living new political-social phenomena that challenge the analyzes that are influenced by the theoretical basis of theory of dependence. Conclusively, among other aspects, it is pointed out that has been made a connection actually between the theory of dependency and the theory of world system.

Keywords: Marx, development, underdevelopment, theory of dependency,
\end{abstract} Latin America

\footnotetext{
${ }^{1}$ Universidade Federal da Paraíba (UFPB).
} 
No âmbito das atividades em alusão aos duzentos anos do nascimento de Marx, cabe lembrar (re)lembrar a recepção da sua teoria social na América Latina, do ponto de vista das abordagens sobre desenvolvimento. Isto significa, substancialmente, ter em conta a influência da metodologia dialética que ele propugnou e o enfoque que, tratando das relações centro e periferia no contexto político-econômico mundial, deu origem a uma escola de pensamento marcadamente latino-americana nos anos 1960/1970: a chamada escola da dependência ou teoria da dependência.

Lançando mão da metodologia dialética, os "dependentistas", ao focarem as relações mundiais de poder, buscando a inteligibilidade dos casos específicos (como os dos 'países não desenvolvidos'), adotaram um pressuposto básico: partir de conceitos e categorias que permitam entender como se estruturam as relações no âmbito da totalidade internacional que agrupa as nações, com este como dizendo respeito, por exemplo, a uma dupla explicação, isto é, tanto do modo como é regido o relacionamento entre países quanto dos padrões (políticos, econômicos, sociais, culturais, ambientais, etc.) que condicionam a vida concreta das pessoas nos contextos nacionais.

Ou seja, levava-se a cabo o esforço analítico de elevação do particular para o geral, no qual as relações parciais (particulares) vão sendo circunscritas em redes de relações e, dessa forma, se vai especificando e delimitando a síntese decorrente, isto é, o todo/a totalidade, mas não como uma amálgama geral confuso e indeterminado, e sim como um conjunto articulado e hierarquizado de interesses, relações e interações. Trata-se de um conjunto cuja compreensão só é alcançada por via da produção de conceitos que ponham a descoberto as variáveis das partes que o compõem e as regularidades da sua reprodução.

Foi através desse modus operandi metodológico que, por exemplo, Theotonio dos Santos delineou uma tipologia das formas históricas da dependência, periodizada em três momentos: a primeira correspondente à dependência colonial, representada pela exportação de produtos in natura e onde o capital comercial e financeiro - coligado com Estados colonialistas dominava as relações entre a Europa e o mundo colonial; a segunda referente 
à dependência financeiro-industrial, consolidada em fins do século XIX, sendo marcada pela ação do grande capital voltado para a captura de matériasprimas/produtos agrícolas; e a terceira, erigida nos anos 1970, concernente à dependência tecnológica-industrial, tendo como característica básica a atuação das corporações multinacionais como investidoras no mercado interno dos países subdesenvolvidos, obrigando estes a importarem máquinas para 0 desenvolvimento de suas indústrias (DOS SANTOS, 1970).

\section{TEORIA DA DEPENDÊNCIA: DIFERENTES VERSÕES E ENFOQUES}

A tese central da teoria da dependência enfatiza que os países dependentes são explorados pelos países centrais, primeiro, no período colonial, por via da apropriação violenta do excedente gerado, depois, contemporaneamente, através do comércio, das relações de troca, do capital financeiro, etc., engendrando o subdesenvolvimento. Contudo,

a teoria da dependência não se caracteriza como uma construção homogênea. Grosso modo, podem ser distinguidas duas versões: uma representada pelas formulações de Fernando Henrique Cardoso, cujo trabalho de base foi escrito em parceria com Enzo Faletto(CARDOSO \& FALETTO, 1981), e outra formulada pelas elaborações de autores como Rui Mauro Marini e Theotonio dos Santos (MARINI, 2000; DOS SANTOS,2000). "Correndo por fora", para além das fronteiras da América Latina, claro está, encontravam-se, por exemplo,teóricos comoSamir Amin e André Gunder Frank.

A versão representada por Cardoso relativiza a determinação externa da dependência/subdesenvolvimento, sublinhando, por exemplo, na América Latina, a ocorrência de uma situação de desenvolvimento dependenteassociado, como resultado da ação dos agentes locais em conexão com forças econômicas externas, o que, ao fim e ao cabo, levou Traspadini(1999) a descrevê-lo como teórico da interdependência. Aliás, o próprio Cardoso (1993), ao definir a sua posição, afirmou que ela desloca o enfoque de um plano do condicionante externo.

A segunda versão referida concede maior peso causal aos fatores externos na determinação das situações de dependência/subdesenvolvimento. Neste sentido, Rui Mauro Marini realça que "a dependência pode ser entendida 
como uma relação de subordinação entre nações formalmente independentes, em cujo âmbito as relações de produção das nações subordinadas são modificadas ou recriadas para assegurar a reprodução ampliada da dependência" (MARINI, 2000, p. 109).

Em função da nova divisão internacional do trabalho, como expressão empírica da realidade latino-americana, foi categorizada - como continuidade da elaboração de Theotonio dos Santos - uma quarta forma de dependência, tendo, entre as suas características, a transferência de recursos e a valorização do capital fictício (AMARAL, 2006). Trata-se de uma perspectiva que procura mostrar as diferenças entre as fases anteriores do capitalismo e a atual, assinalando que a fase dos dias de hoje se distingue por ser fortemente marcada pela financeirização da economia e assente no movimento de generalização especulativa do capital.

Desde esse ponto de vista, os dispositivos analíticos aportados pela categorização mencionada anteriormente permitem apreender as novas manifestações da dependência na América Latina. Neste sentido, o programa político-econômico propagado é claro: rompimento total com a ideia de desenvolvimento tributária do projeto de substituição das importações; supressão dos mecanismos de regulação dos mercados, eliminando-se, por exemplo, os mecanismos de proteção social no mercado de trabalho; configuração do chamado Estado mínimo, etc.

Tendo como referência essas bases, Jaime Osório chamou tal programa de elnuevopatrón exportador latinoamericano, quer dizer, um novo padrão de reprodução do capital, que, em suas linhas gerais, pode caracterizar-se como um novo modelo exportador (OSÓRIO, 2004). Ao fim e ao cabo, isto representa a estruturação de uma nova economia para a região, centrada na especialização, ao invés de na industrialização diversificada levada a efeito no período desenvolvimentista anterior. A tese básica aqui, embora às vezes disfarçada, é que a industrialização/desenvolvimento da América Latina pode ter curso, até de modo mais eficiente, desde que apoiado na vocação primário-exportadora de suas economias, sintonizando-se assim com as tradicionais elaborações teóricas das vantagens comparativas do comércio internacional. 
Dessa forma, revigora-se a noção de intercâmbio desigual, conforme foi formulada por Rui Mauro Marini, visto que a exportação de produtos de baixo valor agregado, intensivos em força de trabalho e recursos naturais, e de mais baixos níveis de produtividade - cujas indústrias são predominantes de países não-centrais - ocorre vis-à-vis à necessária ampliação da importação de produtos de maior valor agregado e de níveis de produtividade superiores (próprios de países centrais), registrando-se assim a transferência do excedente produzido nos países não-centrais para os centrais (provocando desequilíbrios na balança comercial e de serviços) e o decorrente imperativo da atração de capitais que possam fazer frente a estes desequilíbrios.

A atração de tais capitais pode ocorrer, por exemplo, através de investimento direto estrangeiro (IDE) e de empréstimos, por via do lançamento de títulos de dívida e de propriedade. Seja como for, os riscos não são poucos. A propósito, no primeiro caso, embora o IDE faça aumentar a capacidade produtiva nacional, por outro lado, ele também enfraquece a acumulação interna de capital, na medida em que torna crescente a remessa de excedente para o exterior (a repatriação dos lucros) - o que termina por colocar, mais adiante, o problema das contas externas. No segundo caso, os referidos empréstimos tendem a adquirir caráter especulativo, em função da baixa credibilidade e dos riscos de aplicação nos países não-centrais, e são emitidos como papéis de curto prazo e de alta rentabilidade, por causa das elevadas taxas de juros. Desta forma, é comum que, na busca de valorização, se verifique uma intensa volatilidade de tais papéis, com eles entrando e saindo rapidamente dos países, sem estabelecerem nenhum vínculo mais duradouro, o que, consequentemente, pela fuga de capitais que provocam, agrava os problemas das contas externas.

Os desdobramentos dessas políticas, em perspectiva de futuro, não são alvissareiros. Forma-se um círculo vicioso norteado pela atração de capitais externos de curto prazo para fazer frente aos desequilíbrios no balanço de pagamentos, o que é levado a cabo por via do aumento dos juros domésticos, tendo como decorrência, evidentemente, o aumento da dívida interna, além do desestímulo aos investimentos produtivos e ao próprio consumo - o que bloqueia o crescimento e a produção de valor. 
São opções que redundam na manutenção dos chamados superávits primários, voltados ao pagamento de juros, o que também serve de sinalizador à entrada de mais recursos, na medida em que tal sinalizador inspira "confiança" ao capital externo. Chega a ser até quase desnecessário, pelo óbvio, repisar que isto significa subtração de recursos públicos de determinadas áreas (principalmente as sociais) e, por consequência, redução da capacidade de investimento do Estado, e não só no setor social, mas também em áreas imprescindíveis ao desenvolvimento nacional, como é o caso da infraestrutura. No horizonte, portanto, cessada alguma euforia imediata, o que se vislumbra é uma intensa perca de autonomia das políticas nacionais, com o Estado se vendo refém da financeirização externa. Assim, o resultado não pode ser outro: restringe-se o crescimento interno, em virtude dos déficits em conta corrente e da necessidade de manter as taxas de juros elevadas como forma de atrair o capital especulativo para cobri-los.

\section{TEORIA DA DEPENDÊNCIA: RETROSPECTIVA E PROSPECTIVA}

A teoria da dependência aparece como uma crítica à tradicional visão do subdesenvolvimento como uma ausência de desenvolvimento, que considerava que o "atraso" dos países subdesenvolvidos era explicado pelos obstáculos que neles existiam a seu pleno desenvolvimento ou modernização (Dos Santos, 2000).

Apesar das suas diferentes abordagens, tendo conta as suas distintas correntes, no conjunto, a teoria da dependência tem ideias comuns. Neste sentido, podem ser referidos quatros pontos específicos (BLOMSTRÖM\&HETTNE, 1990). O primeiro deles seria a visão de que o subdesenvolvimento está conectado de maneira estreita com a expansão dos países.O segundo contempla a ideia fundamental de que desenvolvimento e subdesenvolvimento são aspectos diferentes do mesmo processo universal. 0 terceiro aspecto refere-se ao fato de que o subdesenvolvimento não pode ser considerado como a condição primeira para um processo evolucionista. Por fim, o quarto ponto inclui o fato de que a dependência não é só um fenômeno externo, mas ela se manifesta também sob diferentes formas na estrutura interna, nos âmbitos social, ideológico e político. 
Assim, de modo geral, a percepção é a de que o modo de produção capitalista é intrinsecamente desigual/excludente e que desenvolvimento e subdesenvolvimento são fenômenos antagônicos - por se tratarem de situações distintas dentro de uma mesma lógica de acumulação - e, ao mesmo tempo, complementares. Isto decorre do fato segundo o qual a dinâmica mundial da acumulação capitalista tem características que geram o desenvolvimento de determinadas economias, ao mesmo tempo que produzem o subdesenvolvimento de outras. Por ser dessa forma, conclui-se então que a dependência é um aspecto constituinte das economias periféricas diante da acumulação capitalista internacional.

A influência da teoria da dependência foi além da América Latina, mas foi nesta que ela alcançou um significativo destaque. No Chile, o programa da Unidade Popular de Salvador Allende e tendências do governo militar revolucionário peruano incorporavam elementos chaves da teoria da dependência. A teologia da libertação, que surgia no Peru com Gutierrez, tomou-a como sua referência fundamental.

Na sua vertente marxista - capitaneada por Theotonio dos Santos, Rui Mauro Marini, Vânia Bambirra, André Gunder e Samir Amin -, foi um postulado central a tese de que, no âmbito do processo de integração das economias nacionais ao mercado global, as relações de produção são desiguais porque o desenvolvimento de certas partes do sistema ocorre à custa do subdesenvolvimento de outras. As relações tradicionais são baseadas no controle do mercado por parte das nações hegemônicas e isto leva à transferência do excedente gerado nos países dependentes para os países dominantes, tanto na forma de lucros quanto na forma de juros, ocasionando a perda de controle dos dependentes sobre seus recursos. E a geração deste excedente não se dá, nos países periféricos, em função da criação de níveis avançados de tecnologia, mas através da superexploração da força de trabalho (MARINI, 2000).

Em sintéticas palavras, a América Latina que a teoria da dependência procurou analisar tem uma caracterização distinta da que se verifica hoje. Por outro lado, contudo, hoje, como na época das "análises dependentistas", a região está em meio a disputa geopolítica global, com a diferença de que, ao 
contrário dos 1960/1970, os países da região não estão tomados por golpes de estado conduzidos diretamente por militares. Porém, novas formas de corrosão da democracia estão em curso. Este é um quadro que as análises tributárias da teoria da dependência precisam ter em atenção, conhecendo-o em pormenor, para então colocar em realce linhas de inteligibilidade que orientem a ação cidadã.

Deve ser considerado que, após o fim do ciclo ditatorial civil-militar na América Latina, bem como com a passagem da Guerra Fria às páginas da história, essa região iniciou um período de significativa estabilidade (conforme os padrões latino-americanos), naquilo que ficou conhecido, em países como o Brasil, como o 'período da redemocratização'.

Mesmo o Chile, onde só em 1990 o general Augusto Pinochet deixou a Presidência, e também onde - junto com a Argentina - verificou-se uma das ditaduras mais sanguinárias, mesmo esse país passou a viver uma fase não só de acerto de contas com o passado, mas de "amadurecimento" político, com governos da democracia cristã e do partido socialista, que constituíram um agrupamento denominado Concertación.

A Argentina, embora enfrentando períodos de turbulência (no fim do governo Alfonsín, na década Menen e no pós-Fernando de laRúa), manteve, sobretudo com a ascensão de Néstor Kirchner, a sua vida política dentro do plano institucional.

No contexto da América Central, o ocorrido na Nicarágua, em El Savador e na Guatemala exemplifica, ainda mais, o que estou aqui a afirmar. $\mathrm{Na}$ Nicarágua, teve-se que os sandinistas subiram ao poder pela luta armada (1979), foram derrotados eleitoralmente (1989) e voltaram novamente ao poder com Daniel Ortega. Claro, em meio a isso, teríamos que lembrar da ação dos 'contras', financiados pelos Estados Unidos para derrotar a Revolução Sandinista. Em El Salvador, no curso dos desdobramentos do fim da guerra civil, em 1992, a Frente FarabundoMartí de Libertação Nacional (FMLN) chegou ao poder, na década seguinte, com Mauricio Funes. Na Guatemala, a União Revolucionária Nacional Guatemalteca sentou à mesa e, em 1996, a guerra civil cessou, embora a União Nacional, após a assinatura do acordo de 
paz, não tenha conseguido avançar eleitoralmente, como ocorreu com a FMLN em El Salvador.

Em relação ao Brasil, durante os já cerca trinta anos do fim da ditadura civil-militar, o país produziu uma estrutura institucional (impulsionada pela Assembleia Constituinte de 1988 e legislações subsequentes) que the tem permitido, por um lado, a gestão da sua vida política (agitada, muitas vezes) dentro dos marcos constitucionais e, por outro lado, a chancela geopolítica internacional sobre a sua posição diferenciada na América Latina.

Ainda no contexto mais específico da América do Sul, provavelmente seja o Paraguai o país onde se verifica a maior oscilação política, do fim dos anos 1980 até hoje. Tendo vivido um golpe militar, comandado pelo general Alfredo Stroesner, que durou de 1954 a 1989, quando ele foi deposto por um movimento liderado por Alfredo Rodriguez, o Paraguai continuou a viver uma certa instabilidade política, mesmo após a ascensão do primeiro presidente eleito, em 1993, pelo voto popular - o empresário Juan Carlos Wasmosy. Seguiram-se marchas e contramarchas, com tentativas de golpe, rebelião militar, assassinatos, desrespeito à constitucionalidade, etc., tendo no centro figuras como o general Lino Oviedo (falecido em 2013).

Diferentemente disso, no Uruguai, que colocou termo ao regime autoritário instalado em 1973 com a eleição de JulioMaría Sanguinetti (em 1985), seguiu-se um período de equilíbrio político que permitiu feitos ousados, como a rejeição, em plebiscito popular, da tese da privatização dos serviços essenciais - 92\% dos uruguaios decidiram que eles continuariam públicos. Além disso, o país não se furtou a tratar de questões referentes a direitos civis que têm sido postergadas em outras nações da região, a exemplo do aborto.

Some-se ao que foi realçado o fato de ter surgido na América Latina um conjunto de governos que - com as suas particularidades, acertos e equívocos - destoram das perspectivas tradicionalmente hegemônicas na região, e que são impulsionadas pelos Estados Unidos.

Ultimamente, contudo, a configuração política latino-americana aqui assinalada (estabilidade + a existência de governos com perspectivas distintas das defendidas pelos Estados Unidos) vem sendo contrariada, ao mesmo tempo que se tem consolidado a existência de um agrupamento político de 
(extrema) direita com duas tendências: uma que, com antigas e novas palavras, reabilita as passadas ditaduras, defendendo inclusive o regresso dos militares; outra, mais "moderna", tem-se empenhado na estruturação de forças de forças mais ideológicas e programáticas, apresentando-se ao debate público com uma incontinência verbal desmedida. Apesar da diferença entre essas duas tendências, elas mantêm estreitas interlocuções e, em determinados momentos, têm atuado conjuntamente, como fizeram, no Brasil, no processo que derrubou a presidente Dilma Rousseff.

Essa é a conjuntura político-social da América Latina atual, e que desafia, de modo prospectivo, as abordagens que, de alguma forma, têm presente o significado histórico da teoria da dependência.

\section{À GUISA DE CONCLUSÃO}

Se, primariamente, na América Latina, tanto na versão da TD preconizada por FHC como na formulada por Theotonio dos Santos e Rui Mauro Marini, manteve-se um forte foco numa parte do "elo" internacional (a dependente), a renovação das abordagens dependentistas, por sua vez, tem deslocado as análises para uma perspectiva que apanha o sistema económico mundial em sua totalidade.

Segue-se assim, portanto, uma indicação esboçada por André Gunder Frank ainda nos anos 1970, como realçouTheotônio dos Santos, assinalando este, por outro lado, que isso promove o encontro dos dependentistas com a Escola do Sistema Mundo, conforme ela é conceituada por Wallerstein (1990). Esta, digamos, ampliação dos propósitos analíticos da teoria da dependência tem um valorrelevane, principalmente quando consideramos o carácter do capitalismo contemporâneo.

Desde as últimas décadas do século passado, o sistema tem diversificado, em âmbito global, os mecanismos de dependência, lançando mão de "sofistificadas" estratégias amparadas no par inovação tecnológicafinanceirização. Verifica-se que a super-exploração do trabalho, até há algum tempo, própria dos países não-centrais, tem crescido nas sociedades centrais, sendo de referir, neste sentido, o fim do pleno emprego e a generalização da precarização laboral. 
Poder-se-á dizer então que tem acontecido com as abordagens primeiras da teoria da dependência o que é comum às formulações científicas. Não há que se Ihes escrever lápides. Elas modificam-se e, trocando de pena como só acontece com ideias-força, continuam vivas noutros contextos e, às vezes, com outras cores. Para desgosto dos (pós)modernos colecionadores de borboletas, que andam pelos corredores universitários a brandir os discursos pseudo-eruditos em moda e a etiquetar a falência de teorias, é preciso realçar que só os dogmáticos cerram o círculo do conhecimento e produzem sistemas que criam a ilusão de que eles são como a velha esfinge que dizia "decifra-me ou devoro-te". É preciso ter senso, já nem digo de proporções, mas do ridículo mesmo. A criatividade na ciência mede-se também pelo apetite que uma teoria desperta em seus partidários para a reformular, sob o estímulo tanto das lacunas existentes na sua versão primária como em decorrência de ela não responder adequadamente às questões das novas conjunturas.

É no curso desse processo que são construídas análises objetivas e dotadas de capacidade para mostrar que o sistema social produz forças discordantes e cria problemas novos que fazem aparecer formas de conflito e alternativas políticas que desmascaram um dos principais refrões das ideologias dominantes: a perpetuidade do presente, a ideia de que mudanças não são possíveis. A história é, basicamente, movimento e é ela, sob o impulso da racionalidade, que transcende o mundo ideológico da pseudoconcreticidade, cuja marca maior é apresentar a aparência dos fenômenos como sendo a sua essência.

\section{REFERÊNCIAS}

AMARAL, Marisa Silva. A Investida Neoliberal na América Latina e as Novas Determinações da Dependência. Uberlândia, 2006. Dissertação (Mestrado em Economia) - Instituto de Economia, Universidade Federal de Uberlândia.

BLOMSTRÖM, Magnus e HETTNE, Björn. (1990). La Teoría Del Desarrollo en Transición. México: Fondo de Cultura Económica.

CARDOSO, Fernando Henrique (1993). "Teoria da Dependência ou Análise Concreta das Situações de Dependência". In: 
CARDOSO, Fernando Henrique e FALETTO, Enzo (1981). Dependência e Desenvolvimento na América Latina, 6ª edição. Rio de Janeiro: Zahar Editores.

DOS SANTOS, Theotônio (1970). "The StructureofDependence”. In: American Economic Review, maio, pp. 231-236. New York.

DOS SANTOS, Theotonio. A Teoria da Dependência: Balanço e Perspectivas. Rio de Janeiro: Civilização Brasileira, 2000.

MARINI, Rui Mauro (2000). Dialética da Dependência. Petrópolis: Vozes.

OSÓRIO, Jaime (2004). Crítica de la Economía Vulgar - Reproducción del Capital y Dependencia. México: Grupo Editorial Miguel Angel Porrúa.

TRASPADINI, Roberta (1999). A Teoria da (Inter)dependência de Fernando Henrique Cardoso. Rio de Janeiro: Topbooks.

Wallertstein, Immanuel (1990), O sistema económico mundial: a agricultura capitalista e as origens da economia-mundo no século XVI, Porto: Afrontamento. 